\title{
Becoming an Expert, Ambassador or Doing Project Work: Three Paths to Excellence for Students at Artevelde University of Applied Sciences
}

\section{Bart Lievens, Karel Cappelle, Liesbet Matthys}

Bachelor of (International) Business Management, Innovative Education Research, Artevelde University of Applied Sciences, Ghent, Belgium.

\begin{abstract}
Apart from the regular curricula in higher education, institutions increasingly offer additional initiatives or honours programmes for students to excel. Artevelde UAS wants to provide similar additional learning opportunities, in which the notion of excellence is based on reflection, self-direction and 'giving back' to stakeholders. This paper will provide an elaboration of these opportunities, based on three research questions: (1) What project or initiative can be considered as a valid and well-defined form of excelling, (2) How do we formally structure and organize this initiative or project, and (3) How can we evaluate and validate students' experiences of excelling? Students of (International) Business Management at Artevelde UAS can excel in three different ways: by professionalizing and becoming an expert in a certain topic or area, by becoming an ambassador for one particular 21st century skill that has been put forward and highlighted by Artevelde UAS in its mission (global citizenship, entrepreneurship or sustainability), or by cooperating with professional business partners in order to develop and implement a real-life project.
\end{abstract}

Keywords: excellence; higher education; innovation; business student; selfdirection; reflection. 


\section{Introduction}

Apart from the regular curricula in higher education, institutions increasingly offer additional initiatives or honours programmes for students who want to develop and elaborate their knowledge, skills and talents outside of the standard study programme of courses needed to obtain a diploma. In this context, universities and colleges want to provide a challenging and rewarding learning environment so that high-performing students can become highperforming professionals. Providing this kind of environment is also a key concern for the Department of Education in Flanders (Weyts, 2019). Being introduced in the US, the concept of honours programmes was also developed over time in the UK and the Netherlands (Wolfensberger, 2012). Moreover, this concept, together with the notion of 'excellence' programmes has become increasingly apparent in European education (Wolfensberger, p.16); Of course, the term 'excellence' proves to be multifaceted, and even ambiguous, and can be linked to a negative connotation of 'exclusivity' or 'elitism', as opposed to inclusive and democratic values. However, in this paper we would like to propose a concept of excellence initiatives that aspire to provide accessible opportunities to a varied group of students to grow, develop and excel.

Artevelde UAS offers graduate, bachelor and postgraduate study programmes in a variety of topics, ranging from business management and communication to nursery and graphic media. Apart from providing regular courses within the curriculum, it also aims to create learning initiatives that go beyond the curriculum. In its educational vision, Artevelde UAS implements two complementary approaches or objectives to excellence. As a first objective, Artevelde UAS (Vanoverberghe, Slock \& Van Puyenbroeck, 2014) seeks to encourage and stimulate all students to become the best version of themselves as professionals and as global citizens. The personal and professional development of the student within the curriculum is the main focus in this regard. The second way in which our school wants to promote excellence, is by providing extra opportunities to excel to students who demonstrate a higher level of competencies, motivation, and drive. The framework that will be explained further on in this paper, is an illustration of this second approach to excellence.

With this 'framework for excellence', Artevelde UAS wants to provide additional learning opportunities that cater to the needs of students who pursue a more in-depth study of their area of expertise, a more profound development of their professional behavior, and further and more complex challenges with social relevance. This paper will provide an exploration and elaboration of this framework, based on three research questions: (1) What project, initiative or seminar can be considered as a valid and well-defined form of excelling, (2) How do we formally structure and organize this initiative or project, and (3) How can we evaluate and validate students' experiences of excelling? 


\section{Methodology and theoretical background}

The development of this framework, and, consequently, the answer to the three research questions mentioned above, is based on initial research into the topic at hand. A first step of this research project consisted of extensive desk research into the use of excellence programmes in higher education. In addition, we conducted national and international benchmarking with other institutions of higher education on the topic of excellence programmes, the integration of 21 st century skills, and the different ways of validating. Finally, this was complemented by elaborate qualitative research with various stakeholders: external and internal experts on excellence initiatives, various internal policy makers and officers, lecturers, programme managers and coordinators, students, alumni and professionals. Based on this research, we developed a set of guidelines and conditions, and an evaluation grid that is used as a tool for giving efficient feedback during the process and for evaluating and testing students at the end of the excellence project.

The framework is embedded in a number of theoretical concepts that we regard as key to the establishment of an approach to excellence. To start, it is important that students are genuinely motivated to take on an extra project. Ryan and Deci (2000) state that motivation is connected to "innate psychological needs that are the basis for their self-motivation and personality integration, as well as for the conditions that foster those positive processes" (p. 68). These needs are then identified as "needs for competence $[\ldots]$, relatedness $[\ldots]$ and autonomy" (p.68). Lecturers and pedagogical approaches that respond to the combination of these three needs, contribute to the autonomous motivation of their students (figure 1). Autonomous motivation is motivation that arises from a personal stake, from interest or a passion for something. Students with autonomous motivation study because they value the study material, or because they find the study content interesting. Consequently, autonomous motivation has a positive influence on learning (Vansteenkiste, Sierens, Soenens \& Lens, 2007): it is associated with higher success and achievement in learning, more self-directed learning, a higher conceptual understanding, a stronger sense of perseverance, less drop-outs and an increase in psychological wellbeing of the student. It is therefore crucial that the concept of autonomous motivation is integrated in all initiatives, or 'pathways', to excel.
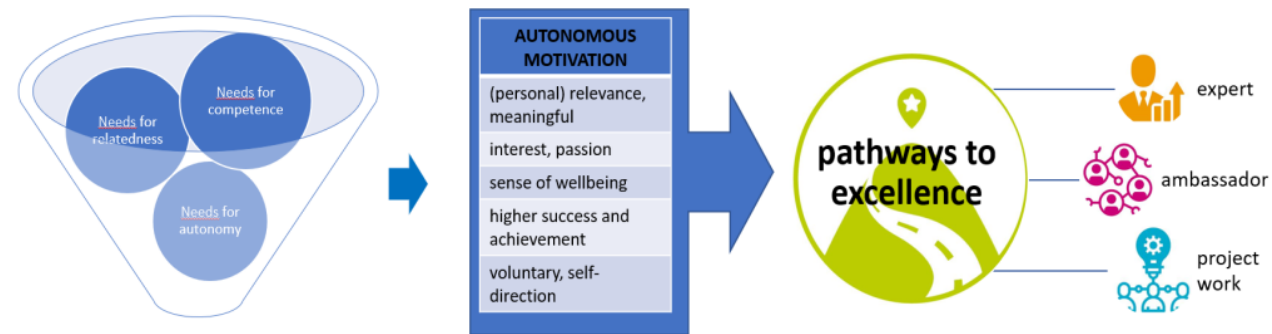

Figure 1. Connection between motivation and autonomy and the pathways to excellence. 
Other research (Hornstra, Weijers, van der Veen \& Peetsma, 2016) asserts that the need for autonomy is somewhat stronger with students who perform well, or who excel. In addition, the need for structure is lower for students who perform well, or who excel.

\section{A valid and well-defined form of excelling}

Inevitably, a general concept such as 'excellence' is difficult to define. To avoid confusion, it is important to note that the Artevelde UAS Framework for excellence excludes certain forms of excelling. For example, students can excel when they obtain a score of 16/20 or more on a certain specific course. Moreover, excelling is significantly different from distinguishing oneself by choosing a certain study programme, course or internship location (Artevelde, 2017). Artevelde UAS does acknowledge and validate these kinds of excelling within the curriculum structure, but it is not the focus of this research project.

In general, students excel when they differentiate themselves from a certain standard. At Artevelde UAS, students can excel on a professional bachelor level, not a master level which is a higher qualification level in the European Qualifications Framework (EQF). Keeping this, and the objectives of this research project, in mind, the definition of excellence as used in the department of business management of Artevelde UAS is as follows:

A student excels if he or she successfully succeeds in an extra-curricular learning opportunity that offers more comprehensive expertise in a particular study topic, or puts the business topic in a broader perspective. This learning opportunity must comply with certain specific characteristics (explained in the next chapter):

1. In the course of the learning opportunity, there is a consistent element of selfregulation and personal process management. Aspects of self-regulation can include, for example: students taking charge of the creation of SMART objectives (Specific, Measurable, Acceptable, Realistic and Time-Bound) and the planning of the initiative, communicating with stakeholders, and adjusting the process when this is deemed necessary.

2. Students constantly have to reflect on the process and on their professional development throughout the learning opportunity

3. After the learning opportunity, students have to commit themselves to giving back their knowledge and experiences to various stakeholders, such as fellow students, potential students, lecturers, or internal services and policy offices within the school. Additionally, this also provides an added value to the school: when students 'give back' their knowledge, the school gains new insights and this might offer possibilities to stay up-to-date and innovative as an institution of higher education. 
The student's effort and commitment to excellence is explicitly acknowledged and rewarded when the student successfully demonstrates that he or she has performed on a bachelor's level of excellence. Students are tested and coached throughout the process, based on an evaluation grid that lists specific learning outcomes linked to three characteristics listed above. The evaluation grid also functions as a tool to assess the student's final achievements.

\section{A Formal Structure: three Pathways to Excellence}

Students can excel in three different ways: by professionalizing and becoming an expert in a certain topic or area, by becoming an ambassador for one particular 21 st century skill that has been put forward and highlighted by Artevelde UAS in its mission (global citizenship, entrepreneurship or sustainability), or by cooperating with professional business partners in order to develop and implement a real-life project. In the following sections, each "path" will be explained in more detail.

The information about the three paths to excellence is communicated to the students on an internal information platform, and in several specific courses related to professional development. For each path to excellence, a description of the initiative is provided, as well as abundant practical information, and a 'job ad' that specifies what kind of person is wanted for each path (detailing the content of the initiative, the skills needed, the procedure, the time period, the evaluation and reward, and the call to apply for this 'position'). Subsequently, students who are motivated to participate can apply for one of the three initiatives, by writing a specific motivation letter. If necessary, the motivation letter is complemented by an additional interview, to select the final participants for the excellence initiative. In both letter and interview, students need to illustrate their interest to participate, by explaining their motivation, and describing the personal and professional objectives they want to integrate in the project. The complete selection procedure is explained in the guidelines provided to coaches and lecturers.

\subsection{Professionalizing / becoming an expert}

In this first pathway to excel, students can distinguish themselves by expanding knowledge and skills related to their area of expertise, their major, which gives them extra qualifications. From the second year of the Bachelor of Business Management, students can specialize and select a "major". The different majors are SME Management, International Entrepreneurship, Law Practice, Logistic Management, Accountancy-Taxation, Finance and Insurance, Marketing and International Business Management.

Examples of this path may include: students of Logistic Management participating in a 24hour hackathon in which a real-life business case is discussed and developed within a diverse and multidisciplinary team, in close cooperation with professionals; Students of Marketing 
looking into the concept of online data analytics and Adwords to create an online marketing plan for an NGO. In all these examples, students focus on the content related to their major. The initiatives in which students can participate can also be organized by external organizations or educational institutions.

Initiatives from this first approach must incorporate the three key features of opportunities for excellence. The initiative itself can often be divided into three separate phases. First, there is a preparatory phase, in which the students make necessary preparation by researching a specific topic and by listing objectives - professional and personal - they want to reach during the process. Next, the focus is on the initiative itself (for example, a series of lectures or a hackathon). To conclude, the students end the process by reflecting on their role, and by "giving back" their knowledge to certain stakeholders.

\subsection{Becoming an ambassador}

The second opportunity for students to excel outside the curriculum entails becoming an active ambassador for certain key 21st century skills in the mission and vision of Artevelde UAS. Artevelde UAS focuses on five pillars: Sustainability, Entrepreneurship, Global Citizenship, IT Literacy, and Analytical Skills and Critical Thinking. Students can choose a project of excellence with a focus on these learning outcomes.

In contrast to the first "path" to excellence, students do not focus that much on the area of expertise of their major. In the second path, students become an ambassador for one of the five 21 st century skills, or a combination thereof. The main way in which students do this is by creating awareness around this topic, and by establishing an active and diverse community that can include students, staff members, and external professionals. In addition, students create, develop and promote initiatives that contribute to the awareness and integration of the selected theme. Self-direction and autonomy are again important conditions that have to be fulfilled, so students are to a great extent responsible for their own track, and for the initiatives they create.

As an example, students at Artevelde were given the opportunity to commit themselves to the topic of sustainability and were responsible for creating a community of students around this topic. In this context, they physically created an SDG classroom with recycled materials and the community of students and lecturers worked on the awareness about the topic of sustainability together. This room has become a hub for promoting other student and staff initiatives towards sustainability.

\subsection{Doing Project Work}

In the third path to excellence, students can differentiate themselves and offer proof of excellence based on a combination of various 21 st century skills. In co-creation with professional partners of Artevelde, students are responsible for developing a project to 
address a 'wicked' problem. As such, the learning environment becomes more complex and varied, and can include multicultural and multidisciplinary aspects. In addition, in-depth and elaborated knowledge about certain business topics is essential. Projects in this category can be divided into different steps: a briefing with the professional client, a preparatory phase in which the necessary knowledge and information is collected, extensive collaboration and communication - both online and offline - throughout the project, creation and implementation of a specific plan or project (for example, the creation of a business plan, a marketing plan, social media strategy ...) for a specific enterprise or NGO, and, finally, the end evaluation and analysis of the project. The projects in this category ideally have a social relevance and are developed in a sustainable way: it is not a one-off initiative, but should be developed over different years, in cooperation with the same professional partner. The students who are involved in such a project are evaluated by both Artevelde and the professional partner.

As an example, a specific project in this category gave students the opportunity to work in cooperation with companies and social organisations in South Africa. After a preparatory phase, students needed to develop a detailed plan on how to tackle certain problems, ranging from purely business procedures, to more societal issues. In this context, the focus is on (intercultural) collaboration and communication, problem-solving and hands-on implementation of solutions.

\section{The Evaluation and Validation of Excellence Experiences}

Throughout the initiative, students can illustrate their work and professional growth in a digital portfolio, that is also used for feedback by the coaches. At the end of the process, the students are evaluated and rewarded. After an oral defense and/or written report, students obtain a reward, and they are put in the spotlight in an award ceremony that brings together students, lecturers, and professional partners. The way in which students are rewarded for their efforts can take different shapes, such as a personal recommendation letter, an endorsement on LinkedIn or a digital badge. In addition, the achievements of the students are highlighted on various public platforms. Students are also encouraged to reach out to a next generation of students to share experiences and inspire other students to also follow a path to excellence.

\section{Conclusion}

To conclude, we considered several factors for the development of excellence opportunities for students. First, a well-defined and legitimate excellence initiative should be an extracurricular initiative in which students demonstrate the skills of self-direction, reflection and 'giving back' and perform on a professional bachelor level of excellence. Secondly, 
excellence activities can be formally divided into three categories: students can excel by elaborating an area of expertise, by becoming an active ambassador for a specific 21 st century skill, or by doing project work in close collaboration with the professional work field. Finally, students get explicitly recognized for their work by the academic and professional field. With this composition, Artevelde UAS provides several opportunities to excel to a variety of bachelor students.

\section{References}

Artevelde University of Applied Sciences (2017). Beleidsnota: kader voor excellentieprogramma's (internal document). Retrieved on 6 July 2019 from https://studentarteveldehsbe.sharepoint.com/:w:/r/sites/ADIOEI/_layouts/15/Doc.aspx?s ourcedoc=\%7B53913060-0907-447E-9B45

FDEB7D7D871C\%7D\&file=TK_beleidsnota\%20excellentietrajecten.docx\&action=def ault\&mobileredirect=true\&DefaultItemOpen=1\&cid=d232f744-8503-4c2d-8c76e136c0f1e $85 b$

Hornstra, Weijers, van der Veen \& Peetsma (2016). Intrinsiek motiveren van leerlingen met verschillende prestatieniveaus en achtergronden. Retrieved on 6 July 2019 from https://www.nro.nl/wp-content/uploads/2015/06/Onderzoeksverslag-Project-intrinsiekmotiveren-def.pdf

Ryan, R. M., \& Deci, E. L. (2000). Self-Determination Theory and the Facilitation of Intrinsic Motivation, Social Development, and Well-Being. American Psychologist, 55 (1), 68-78.

Vanoverberghe, V., Slock, S. \& Van Puyenbroeck, H. (2014). Iedereen moet kunnen schitteren. Op weg naar een talentgevoelige hogeschool, in Thema (3), p. 39-44.

Vansteenkiste, M., Sierens, E., Soenens, B., \& Lens, W. (2007). Willen, moeten en structuur in de klas: over het stimuleren van een optimaal leerproces. Begeleid zelfstandig leren, $16,1-22$.

Weyts, B. (2019). Beleidsnota Onderwijs en Vorming 2010-2024. Retrieved on 16 January 2020 from https://www.vlaanderen.be/publicaties/beleidsnota-2019-2024-onderwijs

Wolfensberger, M.V.C. (2012) Teaching for Excellence. Honors Pedagogies Revealed. Münster: Waxmann. 